Cad.Est.Ling., Campinas, (44):315-323, Jan./Jun. 2003

\title{
A LINGÜÍSTICA TEXTUAL NA REFLEXÃO SOBRE O CONCEITO DE GÊNERO ${ }^{1}$
}

\author{
SANDOVAL NONATO GOMES-SANTOS \\ (UFPA/UNICAMP)
}

"Articuler, articulation, c'est le maître mot d'une époque.

La rémanence d'une ambition totalisante, et humaniste, pour couvrir tout le terrain."

(Henry Meschonnic)

\begin{abstract}
This paper presents an attempt to characterize the themes privileged by brazilian scientific research engaged on discussing the notion/concept of genre, focusing on Text Linguistics contributions about this issue.
\end{abstract}

\section{O CONCEITO DE GÊNERO EM/COMO QUESTÃO}

Gênero tem sido tema recorrente na atual conjuntura intelectual dos estudos lingüísticos brasileiros, o que parece ser motivado em parte pelo interesse que a ele se tem dispensado nos estudos francófonos e anglófonos ${ }^{2}$. Os modos de denominação desse objeto já apontam, de antemão, que o aparente prestígio que se tem atribuído a ele guarda nuanças muito mais diversas do que pode supor uma apreensão imediatista do mesmo. Uma rápida verificação do sintagma em que se localiza o termo gênero, por exemplo, constataria seus modos diversos de configuração em trabalhos que objetivam tratar da questão (ou, pelo menos, de algum de seus aspectos). Podemos ter, desse modo: "a questão do gênero"; "a noção de gênero"; "o conceito de gênero" como

${ }^{1}$ As reflexões expostas neste estudo integram, em grande parte, as que vimos desenvolvendo na tese provisoriamente intitulada "Do retorno da questão do gênero no Brasil: teorização acadêmico-científica e normatização oficial", cuja elaboração insere-se no Programa de Linguiística do Instituto de Estudos da Linguagem da Universidade Estadual de Campinas sob a orientação da professora Ingedore G. V. Koch e a co-orientação da professora Raquel Salek Fiad.

${ }^{2}$ Em Gomes-Santos (2002), assinalamos que, entre os principais aportes teóricos de que se utiliza a pesquisa acadêmica brasileira sobre gênero, na área de lingüística, encontram-se referências aos estudos de Bronckart, Dolz, Schneuwly - em língua francesa -, e de Swales, Fairclough, Halliday - em língua inglesa. 
algumas das expressões possíveis de nomeação desse objeto. Como se não bastasse, o termo é predicado de modos também diversos: "gênero discursivo", "gênero do discurso", "gênero textual", "gênero comunicativo" e mesmo "gênero social".

Em Gomes-Santos (2002), ao apresentarmos um levantamento das tendências dos estudos sobre gênero na pesquisa acadêmica brasileira, destacamos como significativa, no que se refere aos aportes teóricos de que se utiliza essa pesquisa, a complementaridade entre as reflexões bakhtinianas e os estudos advindos da análise de discurso de orientação francófona e/ou estudos mais próximos da lingüística textual (e das disciplinas a ela conexas como análise da conversação, estudos do letramento etc.).

Quanto a esses últimos, autores como Marcuschi, Kaufman e Rodriguez, Koch entre outros - são convocados principalmente em trabalhos que propõem analisar aspectos da organização textual-discursiva de determinados textos/gêneros - repetição lexical, progressão temática, referência textual, topicalização etc. - bem como aspectos particulares de atividades discursivas em suas modalidades falada e escrita. A relevância de questões ligadas ao texto no debate sobre gênero pode ser indiciada ainda pela consideração das percepções de autores que, de algum modo, tematizaram o conceito de gênero.

Assim, na tentativa de confrontar o conceito de gênero do discurso com o de gênero textual, assinalando implicações teórico-metodológicas, epistemológicas e didáticas no uso que se tem feito desses dois conceitos na pesquisa acadêmica, Rojo (2002) adverte para a tendência de diluição das fronteiras entre eles, o que representaria um reducionismo do pensamento bakhtiniano. Para a autora,

A confrontação da perspectiva bakhtiniana com outras perspectivas não muito conflitantes não tem sido preocupação só da LA [Lingüística Aplicada]. Autores ligados à Análise da Conversação, à Lingüística Textual e ao Interacionismo Sócio-Discursivo também têm investido nessa reflexão. Em geral, esses trabalhos apresentam não só um diálogo com a obra bakhtiniana - mais ou menos afinado - como também se preocupam em diferenciar aproximando-os ou distanciando-os - gêneros textuais de gêneros discursivos. (Rojo, op. cit.: 04)

A tendência a que se refere Rojo de sobreposição dos conceitos de gênero textual (ou de texto) e gênero discursivo (ou do discurso) parece explicitar um fenômeno mais amplo que tem marcado desde sempre os estudos do texto e do discurso no domínio das ciências da linguagem, motivado atualmente pelo modo como o objeto-gênero tem-se estabelecido na conjuntura intelectual-acadêmica brasileira. Por se tratar de um conceito que, segundo Maingueneau (2002), "localiza-se na articulação entre a ordem do texto e a ordem do discurso", ele permite que se coloquem em questão as tentativas de dicotomização dessas duas dimensões constitutivas da atividade de linguagem - o texto e o discurso. Nessa direção, a discussão atual sobre gênero pode estar-se configurando como um dos vieses possíveis do diálogo entre a lingüística textual, a análise do discurso e a pragmática, disciplinas tomadas, segundo certas orientações epistemológicas, como domínios absolutamente não passíveis de qualquer forma de aproximação. A possibilidade de um tal diálogo é mencionada por Adam (1999), por exemplo, quando afirma que: 
L'hétérogénéité et la complexité de son objet ont eu progressivement raison des ambitions structuralistes initiales de la linguistique textuelle : élaborer, d'une part, une 'grammaire de texte' et présenter, d'autre part, des 'typologies de textes'. Ce double deuil étant aujourd'hui fait, la linguistique textuelle doit prioritairement se situer par rapport à deux domaines disciplinaires proches: l'analyse de discours et la pragmatique. ${ }^{3}$ (Adam, 1999: 17)

Essa percepção de Adam é assinalada ainda por Brandão (2000) ao sugerir que

(...) numa perspectiva discursiva, o gênero deve ser trabalhado enquanto instituição discursiva, isto é, forma codificada sócio-historicamente por uma determinada cultura e enquanto objeto material, isto é, enquanto materialidade lingüística que se manifesta em diferentes formas de textualização. Vê-se aqui a intersecção interdisciplinar entre a análise do discurso e a lingüística textual. (Brandão, op. cit.: 39)

A aproximação interdisciplinar a que se refere Adam pode ser analisada ainda pelo recurso aos aportes teóricos e metodológicos que vêm subsidiando a reflexão acadêmico-científica mais recente sobre o conceito de gênero, no Brasil. Nessa direção, propomos apresentar, neste estudo, o conjunto de aportes teóricos convocados pelo debate sobre gênero, caracterizando especialmente os modos de inserção dos estudos do texto nesse debate. Para tanto, consideramos um corpus constituído de artigos científicos publicados em periódicos ligados a associações de lingüística (115 artigos) e em coletâneas organizadas com a finalidade de discutir o problema do gênero (42 artigos). Cabe assinalar que a seleção dos artigos orientou-se pelo critério de tematização do conceito de gênero. Tematizar o conceito de gênero consistiu, conforme opção metodológica deste estudo, em estabelecer algum tipo de relação entre o objeto e as questões de pesquisa de que se ocupam os trabalhos e o conceito de gênero, mesmo que esse conceito, em alguns trabalhos, esteja apenas pressuposto. Não bastou, portanto, na eleição dos trabalhos, a consideração da mera nomeação do objeto sob análise como sendo um gênero $\mathrm{X}$ ou $\mathrm{Y}$ (embora esse dado tenha sido também considerado indicador da suposta tematização do conceito de gênero), mas a problematização de algum aspecto dessa nomeação, a explicitação de que se estava tratando do objeto como um gênero. Além disso, a verificação da bibliografia citada nos artigos foi fator relevante na seleção por que optamos. Seguem os quadros dos periódicos e coletâneas em que foram publicados os artigos que constituem o corpus deste estudo.

3 "A heterogeneidade e a complexidade do objeto da lingüística textual desencorajaram suas ambições estruturalistas iniciais: elaborar, por um lado, uma 'gramática de texto' e apresentar, por outro lado, 'tipologias textuais'. Atualmente, uma vez tendo sido abandonado esse binômio, a lingüística textual deve situar-se prioritariamente em referência a dois domínios próximos: a análise do discurso e a pragmática." 
Tabela 1: Artigos científicos por periódico

\begin{tabular}{|l|c|c|c|c|c|c|}
\hline \multicolumn{1}{|c|}{ Periódico/Ano } & 1998 & 1999 & 2000 & 2001 & 2002 & Total \\
\hline $\begin{array}{l}\text { 1. Publicações da ABRALIN } \\
\text { (Boletim 23e 25/ Anais do 2 }\end{array}$ & - & 12 & 1 & 42 & - & 55 \\
$\begin{array}{l}\text { Congresso Nacional e do 2 } \\
\text { Congresso Internacional) }\end{array}$ & & & & & & \\
\hline $\begin{array}{l}\text { 2. Anais do 4 } 4^{\circ} \text { Encontro do } \\
\text { CELSUL }\end{array}$ & - & - & - & 1 & - & 1 \\
\hline $\begin{array}{l}\text { 3. Anais das XVI e XVII Jornadas } \\
\text { do GELNE }\end{array}$ & - & 6 & 23 & - & - & 29 \\
\hline $\begin{array}{l}\text { 4. Estudos Lingüísticos XXVII, } \\
\text { XXVIII, XXIX, XXX, XXXI }\end{array}$ & 3 & 4 & 4 & 12 & 7 & 30 \\
\hline
\end{tabular}

Tabela 2: Coletâneas selecionadas para a constituição do corpus

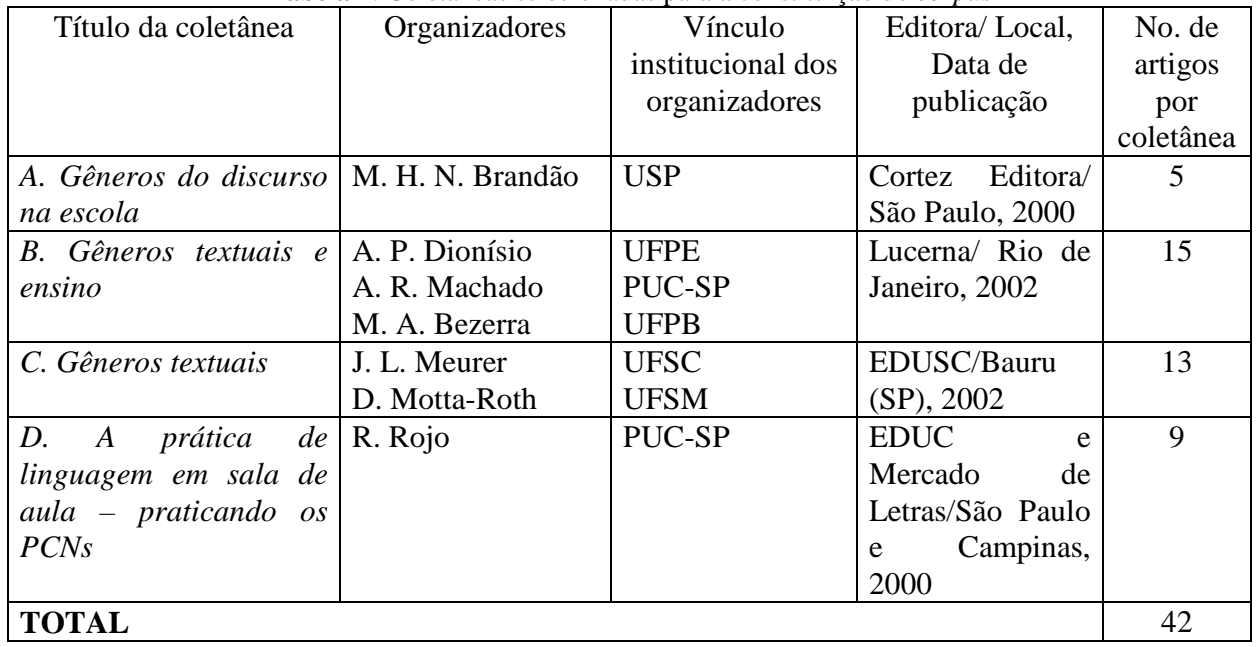

\section{DO TRATAMENTO E DA ORGANIZAÇÃO DOS DADOS}

Os artigos selecionados foram organizados segundo quatro categorias: i) enfoques temáticos; ii) aportes teórico-metodológicos; iii) tipos de dados analisados; iv) contextos institucionais de constituição dos dados analisados. $\mathrm{O}$ estabelecimento dessas categorias decorreu, de um lado, do estudo exploratório que mencionamos (Gomes Santos op. cit.) e da leitura de trabalhos que tiveram a proposta de estabelecer uma espécie de estado do conhecimento sobre a alfabetização no Brasil (Soares 1989); sobre a aquisição e o ensino da escrita (Caron et al.:2000); sobre as relações entre lingüística, ensino de língua e formação de professores (Geraldi et al.:1996) e ainda sobre a circulação do conceito de gênero (Rojo, 2002). De outro lado, a própria leitura dos artigos possibilitou a depreensão de informações que se constituíram elementos para o estabelecimento das categorias mencionadas. Optamos por apresentar, a seguir, 
apenas uma das categorias mencionadas: a relativa aos aportes teóricos e metodológicos a que fazem recurso os trabalhos quando do tratamento da questão do gênero.

\subsection{Aportes teórico-metodológicos do tratamento da questão do gênero}

Organizamos, a seguir, os trabalhos segundo os aportes teóricos que os fundamentam e/ou orientam os procedimentos metodológicos da análise que propõem. Vale assinalar os modos diversos de retomada de aportes teóricos nos trabalhos analisados: eles podem servir para subsidiar a análise dos dados, para discutir o conceito de gênero do ponto de vista teórico ou ainda para construir uma determinada visada teórica/histórica do conceito, entre outras possibilidades. Como veremos, não há como estabelecer limites muito rígidos entre os aportes teóricos de que se utilizam os trabalhos, já que o mais comum é o entrecruzamento de referências teóricas advindas de disciplinas diversas. Dado esse fato, optamos por tomar os aportes teóricos apresentados a seguir em termos de maior ênfaseldominância com que aparecem nos trabalhos.

Inicialmente, pode-se destacar no conjunto dos dados dois agrupamentos que se distinguem dos demais em função do modo como se apropriam dos aportes teóricos: por um lado, os trabalhos que não se utilizam de aporte teórico particular em função da própria natureza da investigação. Trata-se de estudos cujo enfoque circunscreve-se à problematização teórica do conceito de gênero pelo confronto de uma ou de várias correntes teóricas. Nesse caso, pode-se dizer que os aportes teóricos são o próprio objeto sob análise e não têm propriamente função operatório-metodológica para a análise de um corpus no contexto do estudo. Por outro lado, os trabalhos que conjugam diversos aportes teóricos advindos não exatamente dos estudos lingüísticos e/ou não necessariamente ligados à reflexão sobre gênero.

Seguem as tabelas que contemplam esses trabalhos.

Tabela 3: Agrupamentos de trabalhos segundo dois modos de apropriação de aportes teóricos

\begin{tabular}{|l|c|c|}
\hline Dois modos particulares de apropriação de aportes teóricos & $\begin{array}{c}\text { No. de artigos } \\
\text { científicos }\end{array}$ & 8 \\
\hline 1. & $\begin{array}{l}\text { Dada a natureza do estudo, não há aporte teórico } \\
\text { particular para a análise de dados }\end{array}$ & 16 \\
\hline 2. & $\begin{array}{l}\text { Conjugação de aportes teóricos os mais diversos } \\
\text { ligados ou não à reflexão sobre gênero }\end{array}$ & 10,2 \\
\hline
\end{tabular}

Quanto aos trabalhos em que há especificação de aportes teóricos, podemos distribuí-los como a seguir. 
Tabela 4: Aportes teóricos do tratamento do conceito de gênero

\begin{tabular}{|c|c|c|}
\hline Aportes teóricos & $\begin{array}{l}\text { No. de artigos } \\
\text { científicos }\end{array}$ & $\%$ \\
\hline $\begin{array}{l}\text { Estudos em lingüística textual e/ou análise da } \\
\text { conversação conjugados a estudos de tendências } \\
\text { variadas }\end{array}$ & 31 & 19,7 \\
\hline 2. Bakhtin; grupo de Genebra e/ou outros autores & 26 & 16,6 \\
\hline 3. Bakhtin e outros autores de tendências variadas & 28 & 17,8 \\
\hline $\begin{array}{l}\text { 4. Estudos anglo-saxãos (Fairclough, Swales, Bathia etc.) } \\
\text { e/ou autores brasileiros de tendência similar }\end{array}$ & 20 & 12,7 \\
\hline $\begin{array}{l}\text { 5. Bakhtin; teoria do discurso de linha francesa e/ou } \\
\text { estudos de história das idéias e mentalidades }\end{array}$ & 12 & 7,7 \\
\hline 6. Bakhtin e estudos de gênero anglo-saxãos & 7 & 4,5 \\
\hline $\begin{array}{l}\text { 7. Bakhtin e estudos em lingüística textual e análise da } \\
\text { conversação brasileiros }\end{array}$ & 4 & 2,5 \\
\hline 8. Grupo de Genebra e/ou outros autores & 3 & 1,9 \\
\hline $\begin{array}{l}\text { 9. Escola francesa de análise do discurso e outros } \\
\text { estudos enunciativo-discursivos }\end{array}$ & 2 & 1,3 \\
\hline
\end{tabular}

Uma das principais tendências na pesquisa acadêmica sobre gênero é a retomada do pensamento bakhtiniano, associado a outros aportes teóricos. Essa complementaridade é recorrente em grande parte dos trabalhos analisados e assume nuanças diferentes segundo modos de remissão diversos às idéias de Bakhtin e de articulação de seu pensamento com outros estudos. Dada a relevância do recurso ao pensamento bakhtiniano, podemos distinguir dois grandes procedimentos de utilização de aportes teóricos nesta parte do corpus:

1) Trabalhos que fazem recurso ao pensamento bakhtiniano podendo articulá-lo a outros estudos. Nesse caso, a articulação pode constituir-se como:

a) referência a Bakhtin e aos estudos do grupo de Genebra, bem como a menção a outros autores;

b) referência a Bakhtin e a estudos de correntes teóricas e disciplinares diversas.

c) referência a Bakhtin e à teoria do discurso de linha francesa, bem como a autores ligados à história das idéias e das mentalidades;

d) referência a Bakhtin e aos estudos de gênero anglófonos;

e) referência a Bakhtin e aos estudos em lingüística textual e análise da conversação, especialmente brasileiros.

2) Trabalhos que não fazem recurso ao pensamento bakhtiniano, apropriando-se de outros estudos ligados ou não diretamente à reflexão sobre gênero:

a) referência a estudos em lingüística textual e análise da conversação, articulada à menção de outros estudos;

b) referência aos estudos de gênero anglófonos, conjugados a autores brasileiros de corrente similar;

c) referência ao grupo de Genebra e/ou outros autores;

d) referência à escola francesa de análise do discurso e outros estudos enunciativodiscursivos. 


\subsection{Os estudos do texto na reflexão sobre gênero}

Entre os aportes teóricos mencionados, destacamos aqueles relacionados aos estudos em lingüística textual e domínios conexos (análise da conversação etc.), distinguindo duas tendências:

a) a convocação do aporte teórico advindo da lingüística textual elou análise da conversação sem remissão direta e explícita a Bakhtin. Nesse caso, a articulação direciona-se tanto a estudos mais próximos dessas disciplinas - como os da interação, do letramento e da relação entre oralidade e escrita -, quanto àqueles não identificados a princípio com elas. Na primeira das possibilidades, autores brasileiros como Koch, Marcuschi, Paredes Silva etc., bem como estrangeiros como Kaufman e Rodriguez, Goffman, Aphotéloz, etc. dão embasamento para trabalhos de diversos enfoques temáticos, especial e explicitamente, para trabalhos do enfoque que contempla a análise de fenômenos textuais-discursivos (referenciação, progressão temática, dêixis etc.) em gêneros diversos. Na segunda, o referencial teórico da lingüística textual/análise da conversação associa-se tanto a estudos de gênero anglófonos e os respectivos brasileiros de corrente teórica similar (Bathia, Swales, Motta-Roth), quanto a autores não necessariamente ligados à reflexão sobre gênero (Geraldi, Neves etc.) ou ainda a autores da teoria do discurso (Authier, Maingueneau, Brandão, Possenti);

b) a articulação entre Bakhtin e estudos em lingüística textual e análise da conversação brasileiros está presente em estudos que propõem tanto caracterizar determinados gêneros quanto naqueles em que se busca compreender - como no caso da tendência anterior - o funcionamento de um fenômeno da linguagem em um gênero específico, para ficar nesses exemplos. A principal referência quando da tematização dessas questões são os estudos de Marcuschi.

Dada a proeminência com que aparece no corpus, vale assinalar o interesse particular dos trabalhos que fazem remissão ao referencial teórico da lingüística textual/análise da conversação pela análise de fatos da dimensão textual-enunciativodiscursiva da linguagem. Esses trabalhos buscam, a partir da pressuposição de um determinado conceito de gênero e de uma certa prática de linguagem definida a priori como gênero, descrever e analisar fatos de linguagem, tanto os relativos à dimensão propriamente textual implicada na organização de um conjunto de textos/gêneros (continuidade tópica e referenciação, progressão temática, estratégias anafóricas) quanto aqueles ligados ao funcionamento enunciativo-discursivo desses textos/gêneros (estratégias de ataque à face, heterogeneidade, dêiticos, argumentatividade). Em todos os casos - e os exemplos são apenas ilustrativos -, o foco do estudo é o fenômeno de linguagem e o pressuposto parece ser o de que um mesmo fenômeno pode funcionar de modo particular conforme o gênero em que ocorre. Delineia-se, nesse caso, a idéia de que o gênero é um suporte concreto em que se semiotizam fatos de linguagem particulares. 
Talvez seja um tal interesse que esteja na base do próprio modo de definição e de nomeação do objeto-gênero pelos trabalhos que se utilizam do aporte teórico advindo dos estudos do texto. A opção - feita por grande parte desses trabalhos - pela nomeação gêneros de texto (ou textuais) parece indiciar um certo modo de definir o objeto-gênero segundo sua materialidade semiótica constitutiva, o que implica contemplar a dimensão concreta do objeto: assim, a adjetivação "textuais" é a que o define e a que garante as condições de sua existência como objeto sócio-histórico com uma função comunicativa intrínseca.

\section{CONSIDERAÇÕES FINAIS}

Retomando e resumindo, podemos dizer que a consideração dos dados quanto aos aportes teóricos de que se utiliza a pesquisa acadêmica sobre gênero explicita uma pluralidade teórico-epistemológica e metodológica bastante significativa. A pluralidade que apontamos revela-se tanto em termos de diversidade de aportes teóricos convocados quanto nos vários modos de articulação entre eles. De modo geral, a retomada de aportes teóricos para subsidiar a discussão proposta nos trabalhos pode contemplar: i) a filiação explícita a uma corrente teórica e a tentativa de se apropriar de dispositivos metodológicos claramente consolidados como tal (caso dos trabalhos que se utilizam seja do modelo do sócio-interacionismo discursivo proposto pelo grupo de Genebra, seja do modelo CARs proposto por Swales ou ainda daquele chamado modelo tridimensional de análise do discurso proposto por Fairclough); ii) a filiação a disciplinas lingüísticas cujas fronteiras podem ser delineadas (lingüística textual, análise da conversação, teoria do discurso de matiz francês etc.) iii) a filiação a vários autores/aportes como forma de elaborar um conhecimento sobre o estado da arte dos estudos; iv) a conjugação de vários autores não necessariamente ligados aos estudos da linguagem, em geral, e aos estudos do gênero, em particular.

Os entrecruzamentos dos vários aportes teóricos, embora, de um lado, possa revelar uma certa pluralidade teórica como marca da pesquisa acadêmica sobre gênero, parece explicitar, de outro lado, que a reflexão sobre gênero, ao tentar associar saberes teóricos diversos, acaba por produzir um efeito de consenso necessário para legitimar a questão do gênero como pertinente. Esse consenso parece decorrer, entre outras motivações, do próprio modo interdisciplinar pelo qual o conceito tem-se estabelecido na pesquisa acadêmica, uma vez que tanto concilia categorias teóricas nem sempre facilmente articuláveis - como aquelas de texto e de discurso - quanto de certo modo flexibiliza fronteiras disciplinares - entre, por exemplo, os estudos em lingüística (em várias de suas nuanças) e aqueles mais ligados à didática de línguas.

É nessa direção que a conjugação de referências é sintomática do fato de que o conceito de gênero aparece como categoria central para os estudos de linguagem de matiz sócio-discursivo, textual, sócio-interacionista (as designações são as mais diversas), mesmo quando consideradas diferenças quanto aos fundamentos teóricos próprios a cada uma das correntes lingüísticas que tomam o texto e o discurso como objeto principal de estudo. Em outros termos, o conceito de gênero parece emergir - 
como havíamos mencionado - no lugar de articulação entre texto e discurso, o que, de um lado, permite que disciplinas lingüísticas diversas o tomem como categoria pertinente de análise e, de outro, que a lingüística textual e os domínios a ela conexos tomem parte na tematização do conceito. Avaliar as formas e o funcionamento desse fenômeno implica, entre outras tarefas, o investimento na reflexão de cunho epistemológico quando do tratamento da questão do gênero. Isso para que evitemos o risco a que se refere Meschonnic de se produzir uma certa transparência entre conceitos sob a etiqueta cômoda de "articulation".

\section{REFERÊNCIAS BIBLIOGRÁFICAS}

ADAM, J.-M. (1999). Linguistique textuelle - des genres de discours aux textes. Paris: Nathan.

BRANDÃO, M.H.N. (2000). Texto, gêneros do discurso e ensino. In: . (org.). Gêneros do discurso na escola. São Paulo: Cortez Editora, p. 17-45.

CARON, M.F.; FIAD, R.S.; FREIRES, F.N.; GAZELA, S.Ma.; RONCAGLIA, C.B. \& SANTOS, S.N.G. (2000). A produção acadêmica sobre aquisição e ensino da escrita. Estudos Lingüísticos XXIX. São Paulo (SP): Grupo de Estudos Lingüísticos do Estado de São Paulo (GEL), p. 492-497.

GERALDI, J.W. et al. (1996). Retrospectiva: Lingüística, ensino de língua materna e formação de professores. In: DELTA. São Paulo: EDUC, ABRALIN, vol. 12, no. 2.

GOMES SANTOS, S.N. (2002). Algumas tendências dos estudos sobre gênero discursivo na pesquisa acadêmica brasileira. In: Leitura: Teoria e Prática. Revista da Associação de Leitura do Brasil. ALB: Campinas (SP), no. 38 , p. 13-32.

MAINGUENEAU, D. (2002). Retour sur une catégorie: le genre. Comunicação durante o Colóquio Internacional Catégories Descriptives pour le texte. Dijon (FR).

ROJO, R. (2002). Gêneros do discurso e gêneros textuais: questões teóricas e aplicadas. São Paulo: PUC (mimeo.).

SOARES, M. (1989). Alfabetização no Brasil: o estado do conhecimento. Brasília: REDUC. 